\title{
Suitability of Computer-Assisted Analysis of Semen from Mithun
}

\author{
P. Perumal ${ }^{*}$
}

ICAR-National Research Centre on Mithun, Jharnapani, Nagaland (797 106), India

\section{Corresponding Author}

P. Perumal

e-mail: perumalponraj@gmail.com

\author{
Article History \\ Article ID: 3C0280k \\ Received in $02^{\text {nd }}$ October, 2017 \\ Received in revised form $20^{\text {th }}$ November, 2017 \\ Accepted in final form $5^{\text {th }}$ December, 2017
}

\begin{abstract}
The assessment of sperm motility using the conventional microscopical methods is difficult and subjective. High variations have been reported for the estimation of motility parameters of the same ejaculates. Computer assisted semen analysis (CASA) is an accurate technique used for the assessment of the motility and velocity parameters of mithun semen. High number of spermatozoa can be analysed individually in a short period of time. The present study was investigated to assess the motility and velocity parameters of sperm of good and poor quality semen by computer assisted sperm analyser (CASA). Fifty ejaculates were collected from ten matured mithun bulls and were splited into good $(n=25)$ and poor $(n=25)$ quality based on the individual motility and mass activity, i.e. $60 \%$ and above and 2.5 and above, respectively were considered as good quality whereas less than $60 \%$ and 2.5 , respectively were considered as poor quality ejaculates. CASA parameter such as forward progressive motility (FPM; \%), non-progressive motility (NPM; \%), total motility (TM; \%), static sperms (SM; \%), curvilinear velocity (VCL; $\mu \mathrm{m} / \mathrm{sec}$ ), average path velocity (VAP; $\mu \mathrm{m} / \mathrm{sec})$, straight line velocity (VSL; $\mu \mathrm{m} / \mathrm{sec}$ ), linearity (LIN; \%), straightness (STR; \%), amplitude of lateral head displacement (ALH; $\mu \mathrm{m})$, wobble (WOB; \%) and beat cross frequency (BCF; $\mathrm{Hz}$ ) were measured by CASA analyser. Result shown that these parameters varied significantly $(p<0.05)$ between the good and poor quality semen and good quality semen has significantly $(p<0.05)$ higher value than poor quality ejaculates. It was concluded that good quality sperm has higher functional sperm structures to mobilise forward direction and faster to achieve the successful fertilization.
\end{abstract}

Keywords: Mithun, computer assisted sperm analysis, motility and velocity parameters

\section{Introduction}

Mithun (Bosfrontalis) is a domestic, free-range, bovine species present in the North-Eastern Hill (NEH) region of India and is considered as to have originated about 8000 years ago from wild Indian gaur. Estimation of motility parameters by manual method with microscope has variation between individuals and there are more chances of human bias. There is need to develop a suitable technique to measure the motility and velocity parameters of spermatozoa to avoid inevitable human bias. Various methods are used to estimate sperm motility and velocity parameters varied from time-exposure or multiple exposure photomicrographies to the very sophisticated CASA techniques (Perumal, 2008; Perumal et al., 2011a; Perumal et al., 2011b). But recent reports suggested that CASA is not only measure the proportion of motile spermatozoa and also estimate the other sperm mobility profiles arrived from individual cells and it have been found it is more predictive of a sample's potential fertility (Perumal, 2008; Perumal et al., 2011a; Perumal et al., 2011b). In the case of the bovine species, specific motion parameters have been reported to be related to fertility (Perumal, 2008; Perumal et al., 2011a; Perumal et al., 2011b; Perumal et al., 2012; Perumal et al., 2016b). In addition to the use of computerized techniques to predict semen fertility, CASA provides a useful tool to study the effects of various in vitro procedures on motility profiles and the phenomenon of sperm hyper-activation. Spermatozoa FPM along with some velocity profiles are very important for the spermatozoa to achieve fertilization. Spermatozoa kinematic parameters such as PFM, VSL, VCL, ALH and LIN were correlated with bull fertility (Perumal, 2008, Perumal et al., 2011a Perumal et al., 2011b; Perumal et al., 2016a).

Significantly higher ALH and VCL in spermatozoa suggest that major bending of the mid piece and large amplitude of lateral head displacement and this suggest the hyperactivation of the spermatozoa. Hyperactivation in turn implies high ATP production (high energy condition) of the spermatozoa and is important for sperm penetration through cervical mucus and fuse with the oocytes (Aitken et al., 1985). Spermatozoa motility and velocity reflect their mitochondrial function indirectly. Some study indicated that in cattle species, some specific CASA parameters have been observed to be related to fertility (Perumal, 2008; Perumal et al., 2011a; Perumal et al., 2011b). Study of motility and velocity parameters by computer assisted sperm analyser was reported in various domestic 
animal species (Perumal, 2008; Perumal et al., 2011a; Perumal et al., 2011b; Anil Kumar et al., 2011; Domosławska et al., 2013). Further, perusal of literatures revealed that no information on motility and velocity parameters measured by computer assisted semen analyser (CASA) in mithun species. Hence, the objective of this study was to assess the motility and velocity parameters measured by computer assisted semen analyser to pursuit future sperm preservation protocols in mithun.

\section{Material and Methods}

Ten apparently healthy mithun bulls of 3 to 5 yr of age (493-507 $\mathrm{kg}$ ) with good body condition (score 5-6) were selected from the herd in mithun farm, ICAR-NRC on Mithun, Jharnapani, Nagaland, India. They were maintained under uniform feeding and management conditions. Each experimental animal was fed as per the farm schedule. A total of 50 ejaculates were collected from matured $(n=10)$ bulls via transrectal massage method. The semen ejaculates were categorized into good $(n=25)$ and poor quality $(n=25)$ based on the mass activity and individual motility. Mass activity more than 2.5 and above and individual motility $60 \%$ and above were considered as good quality ejaculates whereas poor quality ejaculates were had less than 2.5 and $60 \%$, respectively.

The sperm motility and velocity parameters were evaluated by Hamilton Thorne Sperm Analyser (HTM-IVOS, version IVOS 11, Hamilton Thorne Research, USA). This CASA system consists of a phase-contrast microscope, camera, mini-therm heating stage, image digitizer, and computer saving and analyzing the data. The software was set as follows: temperature of analysis $(ㅇ)$ :37.0, Chamber type :Leja 4, frame rate $(\mathrm{Hz}): 60$, fields acquired :10, minimum static contrast :35, number of frames $: 30$, STR (\%) :70, minimum cell size (pixels) :5, VAP cut - off $\left(\mu \mathrm{m} \mathrm{s}^{-1}\right): 30$, VSL cut-off $\left(\mu \mathrm{m} \mathrm{s}^{-1}\right): 15$, Prog.min VAP $(\mu \mathrm{m} / \mathrm{s}): 50$, magnification :1.89 and cell intensity $: 80$.

The sperm concentration was estimated with a phasecontrast microscope (Nikon, Eclipse 80i; 400× magnification) immediately after semen collection. Semen $(25 \mu \mathrm{L})$ was extended with $50-100 \mu \mathrm{L}$ of Tris (formulated for bull semen) and $5 \mu \mathrm{L}$ of this extended semen sample was placed into a prewarmed $\left(37^{\circ} \mathrm{C}\right)$ chamber of disposable Leja slide (IMV, France) and was permitted to settle on the heating plate $\left(38^{\circ} \mathrm{C}\right)$ just prior to analysis. CASA parameters such as percentage of TM, percentage of spermatozoa with FPM, VSL, VAP, ALH, VCL, BCF $(\mathrm{Hz})$, LIN (\%) and STR (\%) were estimated. A minimum of 200 spermatozoa were analysed minimum of two different drops from each semen sample for each ejaculates. The number of objects incorrectly identified as spermatozoa were deleted manually and analysed accordingly.

The results were analysed statistically and expressed as the mean \pm S.E.M. Significant difference between the good and poor semen samples were estimated with the student ' $t$ ' test with the use of SPSS (ver. 15.0) computer program
(SPSS, Chicago, IL). Differences with values of $p<0.05$ were considered as significant statistically after angular transformation of percentage data. Correlation between the CASA parameters was analysed with Pearson's correlation coefficient. Differences at $(p<0.05)$ were considered to be statistically significant.

\section{Results and Discussion}

The percent of TM and FPM were significantly $(p<0.05)$ higher in good than in poor quality semen and NPM and SM were higher in poor than in good quality semen (Table 1). Similarly, velocity parameters were significantly $(p<0.05)$ higher in good quality semen in mithun species. Similar report was observed in various domestic animal species (Perumal, 2008; Perumal et al., 2011a; Perumal et al., 2011b; Anil Kumar et al., 2011; Domosławska et al., 2013). Thus, it may enhance the quality of semen by preserving efficiently during artificial insemination procedure. High variations have been reported for the estimation of motility parameters of the same ejaculates (Perumal, 2008; Perumal et al., 2011a; Perumal et al., 2011b). CASA is an accurate technique and high number of spermatozoa can be analysed individually in a short period of time (Verstegen et al., 2002).

The sperm mobility phenotype can be attributed to specific

\begin{tabular}{|c|c|c|}
\hline $\begin{array}{l}\text { CASA motility and velocity } \\
\text { Parameters }\end{array}$ & $\begin{array}{l}\text { Good quality } \\
\text { semen }(n=25)\end{array}$ & $\begin{array}{l}\text { Poor quality } \\
\text { semen }(n=25)\end{array}$ \\
\hline $\begin{array}{l}\text { Forward Progressive motil- } \\
\text { ity (\%) }\end{array}$ & $60.63 \pm 2.55^{a}$ & $31.50 \pm 2.16^{b}$ \\
\hline $\begin{array}{l}\text { Non Progressive motility } \\
(\%)\end{array}$ & $17.98 \pm 2.11$ & $20.38 \pm 1.86$ \\
\hline Total Motility (\%) & $78.62 \pm 2.16^{a}$ & $51.88 \pm 1.62^{\mathrm{b}}$ \\
\hline Static sperms (\%) & $21.38 \pm 2.28 \mathrm{a}$ & $48.12 \pm 1.88^{b}$ \\
\hline $\begin{array}{l}\text { Curvilinear velocity (VCL) } \\
\left.(\mu \mathrm{m} \mathrm{sec})^{-1}\right)\end{array}$ & $186.13 \pm 4.31^{\mathrm{a}}$ & $126.86 \pm 3.75^{b}$ \\
\hline $\begin{array}{l}\text { Straight line velocity (VSL) } \\
\left.(\mu \mathrm{m} \mathrm{sec})^{-1}\right)\end{array}$ & $89.32 \pm 2.72^{\mathrm{a}}$ & $53.36 \pm 2.44^{b}$ \\
\hline $\begin{array}{l}\text { Average path velocity (VAP) } \\
\left.(\mu \mathrm{m} \mathrm{sec})^{-1}\right)\end{array}$ & $114.64 \pm 3.85^{\mathrm{a}}$ & $85.15 \pm 2.67^{b}$ \\
\hline Linearity (LIN) (\%) & $48.17 \pm 0.95^{\mathrm{a}}$ & $42.26 \pm 1.59^{b}$ \\
\hline Straightness (STR) (\%) & $78.25 \pm 1.75^{\mathrm{a}}$ & $62.63 \pm 1.68^{b}$ \\
\hline Wobble (WOB) (\%) & $61.48 \pm 1.29^{a}$ & $67.26 \pm 1.51^{\mathrm{b}}$ \\
\hline $\begin{array}{l}\text { Amplitude of lateral head } \\
\text { displacement ( } \mu \mathrm{m})\end{array}$ & $8.61 \pm 1.18^{a}$ & $4.54 \pm 1.26^{b}$ \\
\hline $\begin{array}{l}\text { Beat/cross frequency (BCF) } \\
(\mathrm{Hz})\end{array}$ & $28.26 \pm 1.35^{\mathrm{a}}$ & $21.14 \pm 1.22^{b}$ \\
\hline
\end{tabular}

Figures with same superscripts $(a, b)$ do not differ significantly in rows 
sperm velocity profiles of single sperm as estimated using CASA. Motion parameters such as VSL, LIN and BCF contribute to overall improvement of sperm motility profiles in breeding males because all these were significantly correlated with sperm mobility. Various types of sperm mobility representing VCL, VSL, VAP, LIN, STR, WOB, ALH, BCF and others have been displayed in Table 1. The parameters VSL, VAP, VCL, LIN, and BCF were also significantly higher for the males classified as high mobility as compared with the low-mobility males. The parameter LIN is a measure of linearity. BCF parameter suggests the times the sperm track crosses the smoothed path, both of which indicate linear progression. Thus, high-mobility sperm swim faster and straighter than did low-mobility sperm. This may be biologically important as the sperm phenotype on the basis of investigation with whole single ejaculates is predictive of fertility (Froman and Feltmann, 1998; Froman et al., 1999).

Semen samples with high FPM and TM had positively and significantly correlated with other velocity profiles in good quality semen (Table 2). The samples with high PFM had significantly higher progressive velocity, track speed and VAP. This was similar to the findings of Anil Kumar et al. (2011) and Perumal et al. (2011a), Perumal et al. (2011b) for path velocity. Average path velocity was positively and significantly correlated with ALH, track speed and progressive velocity. Positive and significant correlation observed between VSL, VAP, VCL and ALH and between ALH with VAP, VSL and VCL and between VSL and VCL suggested that the mobility and velocity profiles were correlated and interrelated among them and with ALH. Linearity was significantly and negatively correlated with ALH. Anil Kumar et al. (2011) and Perumal et al. (2011a), Perumal et al. (2011b) observed a negative correlation similar to the present study between LIN and ALH. Highly significant negative correlation was existed between VCL and LIN. A similar result was observed in the present study. But in poor quality semen, there was non-significant correlation was observed between the motility and velocity parameters except between VCL \& VSL, VAP, ALH and BCF

Table 2: Correlation between the motility and velocity parameters of sperm of good quality semen of mithun

\begin{tabular}{|c|c|c|c|c|c|c|c|c|c|c|c|c|}
\hline & FPM & NPM & TM & SM & $\mathrm{VCL}$ & VSL & VAP & LIN & STR & WOB & ALH & $\mathrm{BCF}$ \\
\hline FPM & 1.00 & $-0.76^{*}$ & $0.73^{*}$ & $-0.75^{*}$ & $0.65^{*}$ & $0.68^{*}$ & $0.70^{*}$ & 0.52 & $0.69^{*}$ & $0.64^{*}$ & $0.66^{*}$ & $0.68^{*}$ \\
\hline NPM & & 0.100 & -0.12 & 0.12 & -0.04 & -0.05 & -0.10 & 0.05 & 0.22 & -0.28 & -0.05 & -0.11 \\
\hline TM & & & 1.00 & $-0.98^{*}$ & $0.94^{*}$ & $0.95^{*}$ & $0.96^{*}$ & $0.75^{*}$ & $0.83^{*}$ & $0.70^{*}$ & $0.95^{*}$ & $0.93^{*}$ \\
\hline SM & & & & 1.00 & $-0.94^{*}$ & $-0.95^{*}$ & $-0.95^{*}$ & $0.75^{*}$ & $0.84^{*}$ & $-0.70^{*}$ & -0.95 & -0.93 \\
\hline VCL & & & & & 1.00 & $0.99^{*}$ & $0.98^{*}$ & $-0.83^{*}$ & -0.84 & $0.64^{*}$ & $0.97^{*}$ & $0.95^{*}$ \\
\hline VSL & & & & & & 1.00 & $0.98^{*}$ & $-0.75^{*}$ & $-0.82^{*}$ & $0.67^{*}$ & $0.97^{*}$ & $0.96^{*}$ \\
\hline VAP & & & & & & & 1.00 & $-0.80^{*}$ & $-0.91^{*}$ & $0.75^{*}$ & $0.98^{*}$ & $0.97^{*}$ \\
\hline LIN & & & & & & & & 1.00 & $0.79^{*}$ & -0.46 & $-0.77^{*}$ & $-0.73^{*}$ \\
\hline STR & & & & & & & & & 1.00 & $-0.91^{*}$ & $-0.86^{*}$ & $-0.87^{*}$ \\
\hline WOB & & & & & & & & & & 1.00 & $0.73^{*}$ & $0.75^{*}$ \\
\hline ALH & & & & & & & & & & & 1.00 & $0.94^{*}$ \\
\hline $\mathrm{BCF}$ & & & & & & & & & & & & 1.00 \\
\hline
\end{tabular}

* Correlation coefficient were significant, $p<0.05$

and between LIN and STR (Table 3).

Spermatozoa FPM with some velocity profiles are important for the spermatozoa to achieve fertilization. Spermatozoa kinematic profiles, VSL, FPM, VCL, LIN and ALH were correlated with bull fertility (Perumal, 2008; Perumal et al., 2011a; Perumal et al., 2011b). A significantly higher ALH and VCL of the spermatozoa suggested major bending of the mid piece and large amplitude of ALH. This signifies the hyperactivation of the spermatozoa which in turn implies high energy state of the sperm, is important for sperm to penetrate the cervical mucus and fertilize the oocytes (Aitken et al., 1985). Spermatozoa motility and velocity profiles indicate their mitochondrial energy production function potential. In bovine, specific motion parameters have been reported to be related to fertility (Perumal, 2008; Perumal et al., 2011a; Perumal et al., 2011b). But the threshold levels for the CASA profiles were not yet standardized to meet a general consensus.

Recent findings suggested that estimation of motility in an ejaculate may not be considered as a reliable and feasible index for semen quality evaluation. Quantitative and objective assessment of some other CASA profiles derived from observations of individual sperm measured using CASA have been indicated as more interested in predicting semen sample's potential fertility (Perumal, 2008; Perumal et al., 2011a; Perumal et al., 2011b). These parameters are probably important for the progression of sperm cells into estrus cervical mucus as well as binding and penetration of zona pellucida of oocytes (Verstegen et al., 2002). In vitro 


\begin{tabular}{|c|c|c|c|c|c|c|c|c|c|c|c|c|}
\hline & FPM & NPM & TM & SM & $\mathrm{VCL}$ & VSL & VAP & LIN & STR & WOB & ALH & $\mathrm{BCF}$ \\
\hline FPM & 1.00 & $-0.76^{*}$ & 0.58 & -0.05 & 0.05 & 0.07 & -0.06 & -0.007 & -0.01 & -0.03 & 0.01 & -0.05 \\
\hline NPM & & 1.00 & 0.05 & -0.05 & 0.16 & 0.05 & 0.11 & -0.23 & -0.09 & -0.28 & 0.14 & 0.25 \\
\hline $\mathrm{TM}$ & & & 1.00 & $-0.97^{*}$ & 0.22 & 0.06 & 0.14 & -0.31 & -0.14 & -0.37 & 0.17 & 0.27 \\
\hline SM & & & & 1.00 & -0.22 & -0.06 & -0.13 & 0.32 & 0.15 & 0.37 & -0.16 & -0.27 \\
\hline $\mathrm{VCL}$ & & & & & 1.00 & $0.86^{*}$ & $0.96^{*}$ & -0.27 & 0.07 & -0.57 & $0.96^{*}$ & $0.83^{*}$ \\
\hline VSL & & & & & & 1.00 & $0.92^{*}$ & 0.24 & 0.07 & -0.56 & $0.89^{*}$ & 0.64 \\
\hline VAP & & & & & & & 1.00 & -0.10 & 0.12 & -0.30 & 0.97 & $0.81^{*}$ \\
\hline LIN & & & & & & & & 1.00 & $0.82^{*}$ & 0.67 & -0.16 & -0.41 \\
\hline STR & & & & & & & & & 1.00 & 0.14 & 0.10 & -0.16 \\
\hline WOB & & & & & & & & & & 1.00 & -0.40 & $0.94^{*}$ \\
\hline ALH & & & & & & & & & & & 1.00 & $0.81^{*}$ \\
\hline BCF & & & & & & & & & & & & 1.00 \\
\hline
\end{tabular}

* Correlation coefficient were significant, $p<0.05$

fertilization rates of human oocytes have been revealed to correlate positively with sperm velocity (Donnely et al., 1998). In cattle species, sperm mobility and velocity is significantly correlated with the day 59 of non-return rate (Farrel et al., 1998). In humans, BCF and VCL were highly significant for spermatozoa, have higher percentage in zona binding percent and index than for those which failed to penetrate (Fetterlof and Rogers, 1990). In addition to predict fertility, CASA can be a useful and suitable tool to assess the efficacy of various in-vitro protocols to measure motility and the sperm hyperactivation (Farrell et al., 1998).

\section{Conclusion}

Good quality semen has significantly higher value than poor quality ejaculates indicated that good quality sperm has higher functional sperm structures to move faster and forward direction to reach the site of fertilization and successful fertilization.

\section{References}

Aitken, R.J., Sutton, M., Warner, P., Richardson, D.W., 1985. Relationship between the movement characteristics of human spermatozoa and their ability to penetrate cervical mucus and zona free hamster oocytes. Journal of Reproduction and Fertility 73, 441-449.

Anil Kumar, R., Sundararaman, M.N., Patel, D.V., Iyue, M., Kasiraj, R., 2011. Cryopreservation of semen as a venture for conservation of wild and endangered Toda buffalo germplasm. Buffalo Bulletin 30(3), 210-218.

Domosławska, A., Zduńczyk, S., Niżański, W., Janowski, T., 2013. Assessment of semen quality in infertile dogs using computer-assisted sperm analysis by the HamiltonThorne Semen Analyser. Bulletin of the Veterinary Institute in Pulawy 57, 429-432.
Donnely, E.D., Lewis, S.E.M., McNally, J.A., Thompson, W., 1998. In vivo fertilization and pregnancy rates: the influence of sperm motility and morphology on IVF outcome. Fertility and Sterility 70, 304-314.

Farrell, P.B., Presicce, G.A., Brocektt, C.C., Foote, R.H., 1998. Quantification of bull sperm characteristics measured by computer-assisted sperm analysis (CASA) and their relationship to fertility. Theriogenology 49, 871-879.

Fetterlof, P.M., Rogers, B.J., 1990. Prediction of human sperm penetrating ability using computerized motion parameters. Molecular Reproduction and Development 27, 326-331.

Froman, D.P., Feltmann, A.J., Rhoads, M.L., Kirby, J.D., 1999. Sperm mobility: a primary determinant of fertility in the domestic fowl. Biology of Reproduction 61, 400-405.

Froman, D.P., Feltmann, A.J., 1998. Sperm mobility: a quantitative trait of the domestic fowl (Gallus domesticus). Biology of Reproduction 58, 379-384.

Perumal, P., 2008. Cryopreservation of bovine semen with some additives for augmenting fertility. M.V.Sc. Thesis, Orissa University of Agriculture and Technology, Bhubaneswar, Orissa, India.

Perumal, P., Selvaraju, S., Selvakumar, S., Barik, A.K., Mohanty, D.N., Das, S., Das, R.K., Mishra, P.C., 2011a. Effect of prefreeze addition of cysteine hydrochloride and reduced glutathione in semen of crossbred Jersey bulls on sperm parameters and conception rates. Reproduction in Domestic Animals 46(4), 636-641.

Perumal, P., Selvaraju, S., Barik, A.K., Mohanty, D.N., Das, S., Mishra, P.C., 2011b. Role of reduced glutathione in improving post-thaw seminal parameters in poor freezable Jersey crossbred bull semen. Indian Journal of Animal Sciences 81(8), 807-810.

Perumal, P., Selvaraju, S., Barik, A.K., Mohanty, D.N., Das, 
S., Mishra, P.C., Veeraselvam, M., 2012. Reduced glutathione and cysteine hydrochloride on sperm motility and velocity parameters of poor crossbred bull semen. International Journal of Bio-resource and Stress Management 3(2), 145-151.

Perumal, P., Chang, S., Sangma, C.T.R., Savino, N., Khate, K., 2016a. Effect of melatonin on mobility and velocity parameters of mithun (Bos frontalis) semen preserved in liquid state $\left(5^{\circ} \mathrm{C}\right)$. Journal of Experimental Biology and Agricultural Sciences 4(Spl-3), S95-S102.
Perumal, P., Srivastava, S.K., Ghosh, S.K., Baruah, K.K., Bag, S., Rajoria, J.S., Kumar, K., Rajkhowa, C., Pande, M., Srivastava, N., 2016b. Effects of low-density lipoproteins as additive on quality parameters and oxidative stress following cryopreservation of mithun (Bos frontalis) spermatozoa. Reproduction in Domestic Animals 51, 708-716.

Verstegen, J., Iguer-Ouada, M., Onclin, M., 2002. Computer assisted semen analyzers in andrology research and veterinary practice. Theriogenology 57, 149-179. 